\title{
Flexible Approach Path (FAP) for Effective Learning Process in Self Exploration Education System (SEES)
}

\author{
Muhamad Fazil Ahmad* \\ Faculty of Applied Social Sciences, Universiti Sultan Zainal Abidin, Terengganu, Malaysia \\ *Corresponding author E-mail: mfazilahmad@unisza.edu.my
}

\begin{abstract}
The purpose of this study is to develop a Flexible Approach Path (FAP) for effective Self Exploration Education System (SEES) practice for adult learning. In practice, SEES still acutely focuses on transmitting facts instead of encouraging personal exploration. A major barrier to the uptake and integration of new technologies in teaching and learning is the lack of personal experience of online learning on the part of those involved in learning and in the preparation of materials and methods to support the learning. This project addresses by introducing a FAP to support one's own learning, within a semi-formal community structure using $45=40$ end-users. This project focuses on the FAP that includes six dimensions (Invention, Recommendation, Explanation, Demonstration, Understanding, and Recall) which can impact: time; the content of the course; entry requirements; instructional approaches and resources; delivery and logistics each with several aspects. It is applicable to all learning-development situations without being merely restricted to self-instruction or Distance Learning. For the persons who are not familiar with the Flexible Approach, e.g., those who are familiar with face-toface/fieldwork approach, they may wonder why and when the Flexible Approach is applicable. The Flexible Approach is applicable in a case where a learner who can conduct learning on his/her over for certain subjects, thus decreasing the demand for an instructor. A missed learning session does not have to be replaced because the material is already there. They help a trainee who takes a little longer than the other learners to comprehend certain concepts/materials. In addition, it is suitable to be applied in situations when the time is a constraint to limit face to face interaction. In all the above scenarios, the Flexible Approach to learning and development can be used as a very realistic alternative.
\end{abstract}

Keywords: Do-It-Yourself; Flexible Approach; Self Exploration Education System; Learning; Flexible Conceptualization.

\section{Introduction}

Humans are born with different characteristics. They have their own preferences when conducting their life. Similarly, in learning, humans have different styles to construct new knowledge and skills. Some prefer reading books whereas others prefer listening or doing it by themselves. Every people are born as a genius, with curiosity to explore the environment through experimentation. In fact, Self Exploration Education System (SEES) still intensely importance on transmitting facts instead of boosting personal exploration. Conducting learning exploration in a teaching space can be complicated for adult learning or andragogy and limited by welfare, money and workshop infrastructure.

The Flexible Approach or modular teaching is part of teaching strategies [6]. It has been used extensively in the development of self-learning materials or modules for learners in Open and Distance Learning (ODL) [1]. The word "Modular" refers to learning packages consisting of separate parts or units or small chunks which can be put together to form sets of instructional materials. In this part, the study is going to focus on the Flexible Approach in the teaching-learning process. It is applicable to all teaching-learning situations without being merely restricted to selfinstruction or distance learning.

The Modular Approach to teaching and learning is a process in which you take a large topic/educational task and break it down into smaller parts (also known as chunks) with each smaller part being addressed individually. As a lecturer, he or she may view the Flexible Approach as the packaging of small units of a lesson into structured and interactive learner-centered materials which can be used for the students' learning at their own pace or via guided face-to-face learning. Teachers may have come across some features of Flexible Approaches in courses or learning sessions that they have attended.

A typical feature of the Flexible Approach for SEES can start with a preface for the unit, the unit learning outcomes, followed by contents which comprise texts, learning activities, formative and summative assessments, feedback to assessments and ending with a summary of the unit [2]. The main idea behind the Modular Approach is to divide into segments or chunks (divide into smaller portions) the instructional events into some logical sequence that will facilitate the learning process. These features presented in sequence will lead the learner towards achieving the stated learning outcomes.

\section{DIY Learning what is it?}

The ninth Shift of the Malaysia Education Blueprint 2015-2025 (Higher Education) targets Malaysia's higher education institutions to be significant players in the Globalised Online Learning (GOL) field. The GOL focuses on putting Malaysia in a good position to harness the power of online learning, enhancing the quality teaching and learning, lowering the cost of delivery and bringing Malaysian expertise to the global community. However, the major barriers to achieve GOL are lack of personal experience on online 
learning among the online learning users; and on the preparation of materials and methods to support the online learning.

As Do It Yourself (DIY) learners, students take $75 \%$ practice control of their own learning and decide what courses and skills they want to learn [3] (see Fig. 1). The availability of relatively inexpensive online courses through sites like e-Learning Project (KeLIP-UniSZA) helps make it easy for DIY-ers to explore new knowledge areas without the expense of a traditional learning course.

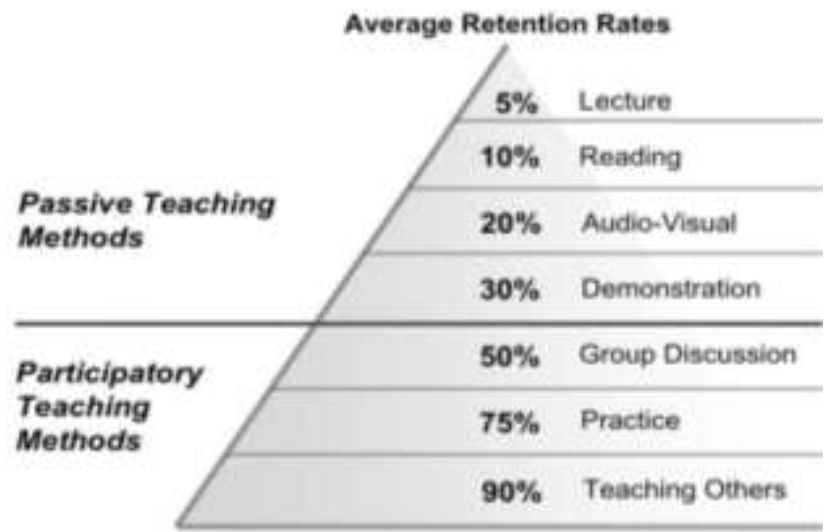

and from National Training Laboratories. Bethel, Maine

Fig. 1: Average Retention Rates of Learning

Many respected primary, secondary and university level, offer Massive Open Online Course (MOOCs) and Udemy.com for free as a way of promoting democratic education and bringing new learning opportunities to the public. These noncredit courses can be found in subjects ranging from computer programming to ancient civilizations, and they are typically a risk-free way to try out a prospective major, develop new skills, or simply expand your general knowledge.

Another feature of the DIY Learning community is hackerspaces: open workspaces where hackers and makers can come together to learn and collaborate, typically in fields like science and technology. Hackerspaces may offer knowledge sharing, social activities, and group projects, much like a more traditional learning environment. The difference is, hackers and makers decide what projects and initiatives are meaningful to them, determining their own curriculum. This is not unlike flipped classrooms, a new approach to education that allows students to guide themselves.

\section{Who is it for?}

The best part of DIY learning is that almost anyone can benefit from it. For some trainees, self-directed learning is an alternative to a formal Learning at any an institution or learning center [4]. For others, it is a way to give learning courses a try and see if a particular skill or discipline is for them. Still, others may choose to take self-directed learning initiatives after learning at the learning institution in order to develop new professional skills or simply to enrich their lives [5].

Pursue only what students' want and need to know. Through FlexiMode, a learner can choose the Learning that directly applies to his/her personal interests and professional goals. If funding traditional institution Learning is not an option, DIY Learning may offer a free or relatively low-cost way to enhance one's skills. DIY learning lets trainees take a stand against the commercialization of learning. DIY movements of MOOC project encourage students to think independently and to rebel against the influence of government or corporate agendas on education.

In some cases, online learning programs can offer the best of both worlds, blending the tried-and-true syllabuses and resources of a learning institution with the DIY flexibility of learning at whatever time and place was chosen. Whatever stand one may take, it is impossible to deny that DIY learning has led to increased accessibility for learners, innovation in course delivery, and a new world of possibilities for independent learners.

However, DIY learning typically does not culminate in a grade, which is a necessary credential for many career paths employers require some sort of formal learning certificate. Self-directed Learning is not applicable to every profession [6]. While many computer programmers may be DIY-ers, it is unlikely to find a self-taught neurosurgeon. A DIY learning requires a great deal of independence and personal drive. A trainee will need to be familiar enough with their chosen discipline to plan and carry out their own course of study, and they will need to hold themselves accountable for reaching the goals they have set.

Self-directed trainees do not have ready access to trainers, tutors, professors, and counselors. While support for DIY-ers is available, a trainee will have to work harder to find a group of knowledgeable peers and mentors to help them.

\section{What is Andragogy?}

Andragogy is the art and science of teaching adult learners. Adult learners have multiple roles which include roles as spouse, parents, employees and members of the society [7]. They possess positive self-concept and are capable of making a decision and being responsible for their own choices. They are also rich in experience and able to relate old experiences with new ones. Andragogy takes into account that adult is self-directing and take responsibility for their own decisions [8] (See Fig. 2). The fundamental concepts of learning involving andragogy are that adults:

- need to know why they need to learn something.

- $\quad$ need to learn experientially.

- $\quad$ approach learning as problem-solving.

- learn best when the topic is of immediate value.

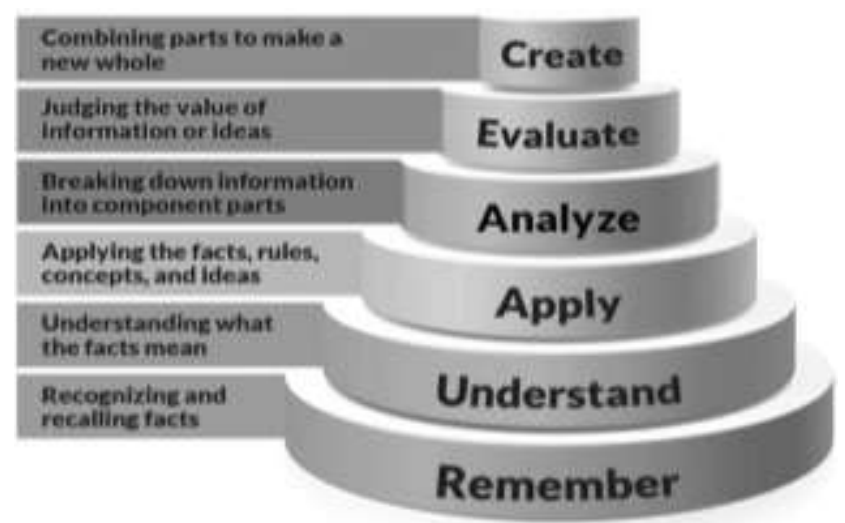

Fig. 2: Level of Taxonomy Bloom

\section{Methodology}

Choosing the correct methodology and methods is the first step and the key in relation to project procedure. In the context of this approach, the application development platform is firstly determined and one suitable development model is chosen. Object oriented programming and modularized programming are adopted in this project. After testing the application, it is evaluated according to its user-friendliness.

\subsection{Selection of development platform}

In relation to the popularity and availability of the user end application, a suitable platform was chosen. Based on the years of efforts by our project team, the system has been successfully established on a PC platform. The new requirement is its establishment on mobile devices such as smart phones and tablet PCs. Currently, the most popular operating systems on mobile devices are Android, iOS, and Windows phone. A software stack is adopted in the Android platform with Linux core providing the 
basic functions and various programmers developing diverse applications [9]. Openness, independence from a service provider, abundant hardware options, no developer restriction, and supporting Google Play are the notable advantages of the Android platform over any of the other available options. Android allows any mobile end manufacturers to join the developing platform, which leads to the diversity of novel applications. This also gathers a wide user base for itself. The internet service is not restricted to the Android platform and the choice of hardware is also significantly plentiful. Manufacturers promote all sorts of products with different features and specialties, but this does not affect the compatibility of software or the data synchronism. Choosing the Android platform minimizes the problems that occur in the programming process, simplifies the developing procedure, and lays the foundation for future popularity of the user end application.

\subsection{Selection of development model}

Over the years, a large diversity of application development models, such as agile methodology, waterfall methodology, extreme programming, and rapid action development have taken shape. While each model has its own advantages and disadvantages, based on the requirements, scale, and urgency of different mobile application development projects, particular models are able to be applied. For example, as for agile methodology, the whole development procedure is divided into several parts. This approach makes it easy to alter the project and reduces the overall risk in relation to the whole project. The waterfall model is best suited to steady and static projects for which the main emphasis is in relation to schedule planning and for which there are no significant changes throughout the entire process. If the application requires a quick delivery, the best choice is rapid action from the developer.

This project is a function-oriented application development aimed to realize an Android application with concrete functions [10]. Hence, the waterfall model is adopted in this project. The project starts with the gathering of related information and background searching. Once the general goal has been settled upon, the move is then towards schedule planning after which the whole project course is completed step-by-step. This model diagram can be seen in Fig. 3.

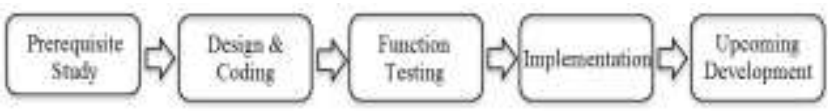

Fig. 3: Waterfall Methodology Model Diagram

Before the design and implementation are initiated, it is important to have knowledge on the background and the current situation for the Flexible Approach Paths. This information is gained by reading the previously reported paper regarding the Modular Approach in the team, as well as studying the paperwork of other Flexible learning systems.

To accomplish this task, the first aspect to be considered is the required functions. The user population of this application is the app users, who require FAP and learning information data. Without a doubt, a great deal of effort is required to be put into the data interaction. The data from the FAP do not come directly from the database. Firstly, the developers upload different data to the server, which would process and save the data. When the user clicks into the application, it will send a requirement to the server for data and information. The remainder of the process is displaying the data in a user-friendly manner. However, it is not sufficient for the user end to merely possess this function. This application should also enable interaction to take place between the users and FAP. As the function of this application is now clarified, the realization of the application is based on these functions.

In relation to the popularity and availability of the user end application, a suitable platform was chosen. Based on the years of efforts by our project team, the system has been successfully established on a PC platform. The new requirement is its establishment on mobile devices such as smartphones and tablet PCs. Currently, the most popular operating systems on mobile devices are Android, iOS, and Windows phone. In this project, the Android platform was been chosen due to the dominances described earlier.

\section{Advantages of Flexible Approach Learning}

The Flexible Approach Learning ensures lectures/learning sessions are delivered accordingly without the presence or lectures/trainers, in conventional lecturers/learning, classes/learning are postponing when the lecturers/trainers are away on official business or due to some personal reason.

Attending hundreds of students in a class that comes from various academic and knowledge background is the most wearisome situation for many lecturers or trainers. Lecturers have to deliver the subject and ensure a bulky syllabus is finished. The lecturers may be delivered at a faster pace, causing some students unable to catch-up the lectures. By using Flexible Approach Learning, they can revise the subject independently. Topics from previous semester can also be browsed, hence, refresh student's knowledge.

\section{Theory of the Flexible Approach: Learning Theories}

What is a learning theory? A learning theory describes how your students learn and describe their actions and behaviour when they learned. Basically, there are five common learning theories:

- Behaviorists - explains learning as a change in behavior.

- Cognitivist - explains learning as an internal mental process. (processing of information, memory, and perception)

- Humanist - explains learning as a personal act to fulfill potential.

- Constructivist - views learning as a construction of knowledge and meaning through experience.

- Social Constructivist - explains learning as a process of interaction with and observation of others in a social context.

(Some description of each learning theory is in order as we cannot presume familiarity).

\section{Relevant Learning Theories of Flexible Approach}

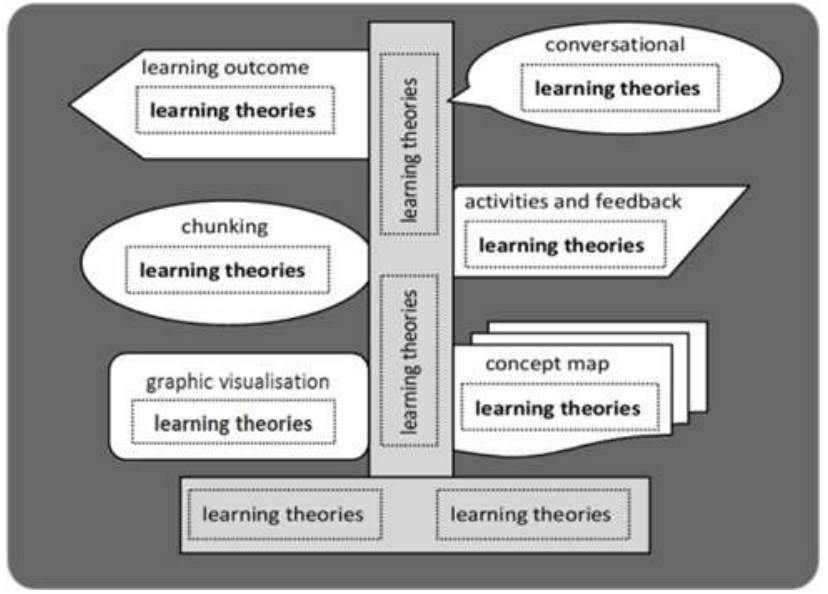

Fig. 4: Learning Theories and the Flexible Approach

Fig. 4 shows the learning theories from which the characteristic features and structure of the Flexible Approach are derived. These theories form the skeletal backbone and the foundational learning principles of the approach [11] 


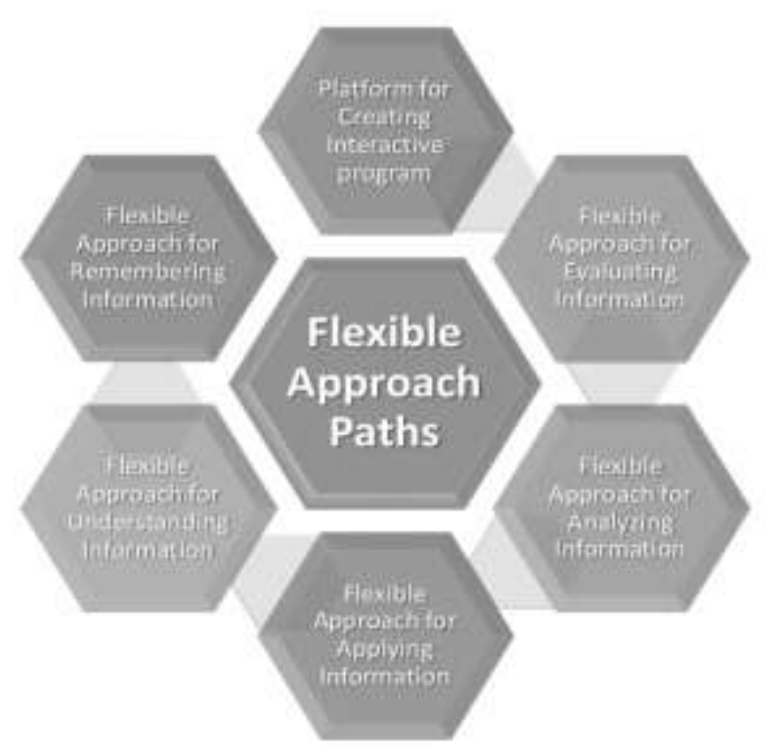

Fig. 5: Flow of Flexible Approach Paths

The Flexible Approach Path can help solve these very typical problems. What if, based on years of learning experience, trainees can already predict some of the potential problem areas in the course that they are going to impart (see Fig. 5). Table 1 shows the Flexible Approach Paths (FAP) consist of 39 attributes coming from 6 dimensions for trainers to refer for developing and designing their Learning programme.

Table 1: The 39 Attributes of the Flexible Approach Paths

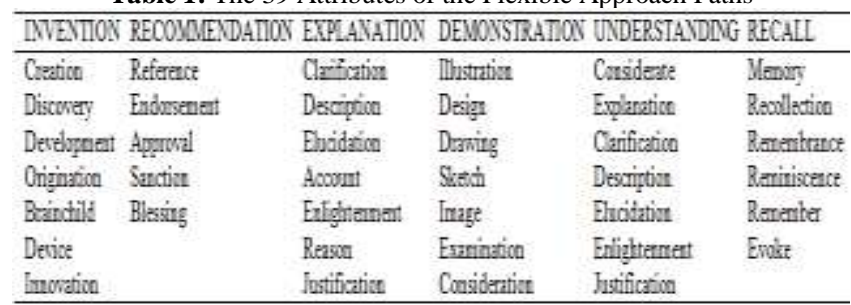

\section{Practicality and Usefulness of FAP for Effective Learning Process of SEES}

The aim is not only to gain insight into how the Flexible Approach evaluates new potential markets, but also to understand how lectures/trainers make sense of, and prioritize, the immense amount of information available. The Flexible Approach Framework will be proposed for Officers, Schools, Colleges Universities and realized by many organizations/institutions and can be further expanded to all field of Learning and Development (T\&D). In this project, the criteria used to determine the attractiveness of a market differ widely. It is importance upon stating that "the linkage between market attractiveness and business success is widely recognized". It can be implied market attractiveness refers to the characteristics and attributes of the market itself. Usually, the criteria used to decide attractiveness depends on the business activity in question. Below follows a presentation of the criteria of which is perceived to be most commonly used for assessing the attractiveness of a market.

The most common way to decide the attractiveness is a usage of performance measures such as market size. For this project, the attractiveness of a market is highly influenced by the market size. The market size is as being one of four factors deciding the attractiveness of a market. The level of attractiveness is by the project managers decided, partly, by looking at the market's size. The underlying metrics used to determine market size vary, but some frequently used indicators include, population size, a total value of sales, and urban population. The market size and market growth are seen as the most commonly used screening criteria. This is also a common way to decide the attractiveness of the project. The market growth as a variable included in several different approaches to Malaysian market selection embraced in reality. The market growth is a factor "considered to be important in assessing the potential attractiveness of a local market".

As is the case with market size and market growth, many researchers argue capital is a criterion of which needs to be evaluated. The income is the level to a large extent influence the attractiveness of a market for T\&D. It can be stated by project managers to evaluate a market's capital when evaluating markets in reality. When entering a local market, the perceived risk associated with a market must be considered by project managers. With this, the risks might diminish a firm's interest to invest in a market. The risk involved in the particular markets is a factor project managers consider when evaluating different alternatives. The risk might be of a political, technological, cultural or economic nature and concerns the environment of the market [12].

Consumer characteristics are further believed to play a role in the Malaysian market selection since a match between the firm's offering and consumers' attitudes and values are crucial for success. The firms which target consumer markets whole competitiveness culminate in a deep understanding of the consumers. Ultimately, a successful establishment in a new market comes down to satisfying consumers' needs and wants, making it reasonable to believe decision-makers investigate this in order to gain insight whether or not the firm can satisfy the consumers [13]. A consumer characteristic is a broad term including many different variables. The homogeneity as one of the main points when segmenting markets, as the needs of a heterogeneous segment might widely differ, this is leaving many consumers dissatisfied. We are of the impression it is not appropriate to define what consumer characteristics are since it might differ what individuals interpret consumer characteristics as [14].

The infrastructure and population density affect the economic attractiveness of the market. An attractive market has an unsatisfied need for the product from the consumers. The first formation Learning concept and the application of this approach in Learning and development program is relatively new in Malaysia. It is also the first interactive for End-user (Do-it-yourself) to increase proficiency and mastery in English Learning practice for nonEnglish speakers in Malaysia. There will be a significant migration from conventional education resources e.g.; books, posters, flips cards to portable electronic devices. Learning and Development (T\&D) process takes a large topic task and breaks it down into smaller parts (also known as chunks) with each smaller part being addressed individually. The interactivity will be captured the attention and promotes the sustainability of information. While the animation stimulates interest and inquisitiveness of the users. Portability and flexibility permit self-directed learning and allows information updating from time to time. The Android-Based Operating System supported by most mobile devices/gadgets [15]. The Flexible Approach was pre-tested for the simulation process with the professional communication T\&D and the IP was registered with Research Management Centre of the university. Inhouse knowledge sharing is growing in popularity as a mean to continuously disseminate knowledge and share best practices for contributing to the community.

\section{Conclusion}

The Flexible Approach or Flexible teaching has been part of teaching strategies for quite some time, but the application of this approach in Learning and development program is relatively new [1]. The objective of this study is to develop a Flexible Approach for effective English Learning practice for non-English speakers. The Flexible Approach is actually being used extensively in the development of self-Learning materials or modules for trainees in the Learning and Development program $(T \& D)$ but yet to be applied in teaching. The word "Flexible" refers to Flexible Learning that can occur anywhere, anyhow, anyway [15]. However, flexible Learning in itself is complex and not as simple 
as this definition implies. The interaction of four components technology, andragogy, implementation strategies and organisational framework - can lead to learner-centered experiences when they are well integrated [4]. FlexiMode for English Language Learning is a Flexible Approach for Effective English Learning Practice designed by Faculty of Applied Social Sciences UniSZA and School of Social and Economic Development UMT is able to ensure students/trainers to understand, speak and learn correct English at anywhere confidently. Simple requirements are devoted some hours every day, as per your convenience, in surrounding your quiet home \& soon you will be a master of English.

\section{Acknowledgement}

The author would like to thank the Research Management, Innovation and Commercialization Centre, Universiti Sultan Zainal Abidin, Terengganu, Malaysia for providing the financial assistance to support the publication fee of this article. Also, a special appreciation to the School of Social and Economic Development, Universiti Malaysia Terengganu, Terengganu Malaysia, which makes this publication possible.

\section{References}

[1] Arends, R., \& Castle, S. (1991). Learning to teach. McGraw-Hill.

[2] Casey, J., \& Wilson, P. (2005). A practical guide to providing flexible learning in further and higher education. Quality Assurance Agency for Higher Education Scotland, Glasgow. http//www. enhancementthemes.

uk/documents/flexibleDelivery/FD_Flexible_ Learning_JCaseyFINALWEB. pdf.

[3] Chang, G., Tan, C., Li, G., \& Zhu, C. (2010). Developing mobile applications on the Android platform. In X. Jiang, M. Y. Ma, \& C. W. Chen (Eds.), Mobile Multimedia Processing. Berlin: Springer, pp. 264-286.

[4] Collis, B., \& Moonen, J. (2012). Flexible learning in a digital world: Experiences and expectations. Routledge.

[5] Corrigan, A. (1993). Training the DIY apporach. Learned Publishing, 6(1), 29-33.

[6] Hartung, T., Bremer, S., Casati, S., Coecke, S., Corvi, R., Fortaner S., Gribaldo, L., Halder, M., Hoffmann, S., Roi, A. J., \& Prieto, P. (2004). A modular approach to the ECVAM principles on test validity. Altern Lab Anim, 32(5), 467-472.

[7] Hu, W., Chen, T., Shi, Q., \& Lou, X. (2010). Smartphone software development course design based on android. Proceedings of the IEEE 10th International Conference on Computer and Information Technology, pp. 2180-2184.

[8] Knowles, M. (1996). Andragogy: An emerging technology for adult learning. Routledge.

[9] Lee, W. M. (2012). Android Application Development Cookbook: 93 Recipes for Building Winning Apps. John Wiley and Sons.

[10] Merriam, S. B. (2001). Andragogy and self-directed learning: Pillars of adult learning theory. New Directions for Adult and Continuing Education, 2001(89), 3-14.

[11] Ahmad, M. F. (2015). Komunikasi Strategik Latihan dan Pembangunan. UniSZA Press.

[12] Ormond, S. (2002). Supporting students in online, open and distance learning. Routledge.

[13] Wadsworth, Y. (2016). Do it yourself social research. Routledge.

[14] Wallace, M. J., \& Bau, T. H. (1991). Training foreign language teachers: A reflective approach. Cambridge University Press.

[15] Willems, J. (2005). Flexible Learning: Implications of "when-ever","where-ever" and "what-ever". Taylor and Francis. 